\title{
Building on solid foundations
}

\author{
Steffen Pauly
}

Published online: 18 January 2012

(C) Springer-Verlag 2012

In the continuing move to adapt the journal to a changing environment, the editorial team of ACQUAL has been expanded. This gave a new role to Paul De Bièvre, who is now the Founding Editor-in-Chief. The expansion includes the appointment of Hendrik Emons as Editor-in-Chief as well as Lindsey Mackay and Lorraine Turner as Associate Editors. Heiner Korte will continue as the pivot of the Editorial Team in his function as Editor-in-Chief and Managing Editor. The motivation of this expansion will be outlined in another Editorial by Hendrik Emons.

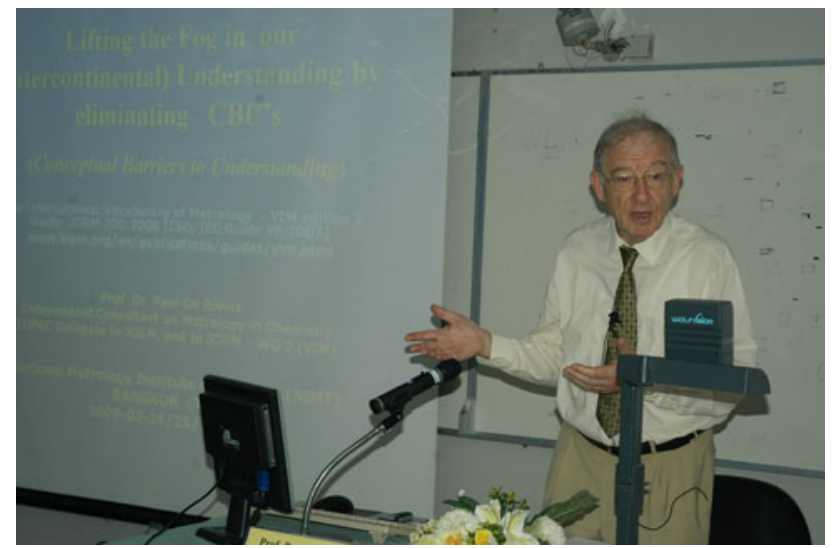

(photo reprinted with permission of Piya Bhusakaew, Head of NIMT Information Technology Centre, National Institute of Metrology, Thailand)

Here, I would like to honor and acknowledge, personally and on behalf of Springer, the 16 years that Paul

S. Pauly $(\bowtie)$

Springer, Tiergartenstrasse 17,

69121 Heidelberg, Germany

e-mail: steffen.pauly@springer.com
De Bièvre has served as Editor-in-Chief of ACQUAL, and the 142 contributions he has written for the journal during this time. As a co-founder of the journal, he has decisively shaped the success of ACQUAL, as pointed out in an Editorial on the occasion of his 65th birthday [1]. Within the scope of my Editorial, it is impossible to give due credit to all of Paul De Bièvre's numerous activities and achievements in the field of metrology in chemistry. However, there is one particular aspect of his professional life that strikes me as very remarkable. That is, his ability as a (co-)founder of successful undertakings. He demonstrated this ability not only through ACQUAL, but also by IMEP (International Measurement Evaluation Programme), EURACHEM (A Focus for Analytical Chemistry in Europe), or CITAC (Cooperation on Traceability in Analytical Chemistry). And certainly his professional life has been devoted to the very foundations of measurement science! It therefore seems apt for such a founding personality to become Founding Editor-in-Chief, and we look forward to his 150th contribution in the near future!

To build the journal further on these solid foundations, in cooperation with Heiner Korte and the new Associate Editors, will be the task of Hendrik Emons as the new Editor-in-Chief. Since 2003, he is the Head of the Reference Materials Unit of the European Commissions' Joint Research Centre, Institute for Reference Materials and Measurements (IRMM), located in Geel, Belgium. There he is heading a truly multidisciplinary team that realizes programs on the development, production, and certification of reference materials for a very broad range of application areas, from impact toughness of steel to proteins in human serum, from elemental and nuclear to microbiological analysis and from nanoparticle sizing to GMO quantification. 


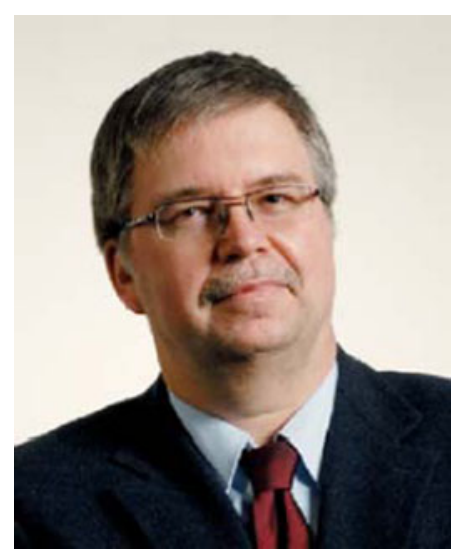

Hendrik Emons studied chemistry and gained a $\mathrm{PhD}$ in Physical Chemistry and Electrochemistry at the MartinLuther University of Halle, Germany, in 1984 and a Habilitation in Analytical Chemistry at the University of Leipzig, Germany, in 1988. He was Docent for Analytical Chemistry at the University of Leipzig and in 1991/92, Humboldt Fellow and Visiting Professor at the University of Cincinnati, OH, USA. Afterward, he was in charge of the German Environmental Specimen Banking Project at the Research Centre, Jülich (Germany), and 2001/2002 Deputy Head of the newly founded Institute for Phytosphere Research there. In addition to his duties at IRMM, he is teaching as Associate Professor at the University of Duisburg-Essen, Germany, organizing conferences and serving as member of or chairing various scientific boards and advisory groups. He published more than 200 scientific publications and gave more than 240 lectures at conferences and other scientific meetings. Hendrik Emons received several awards, such as AOAC's Reference Materials Achievement Award 2009, and is a Fellow of the Royal Society of Chemistry and elected member of the Leibniz Society of Sciences, located in Berlin (Germany).

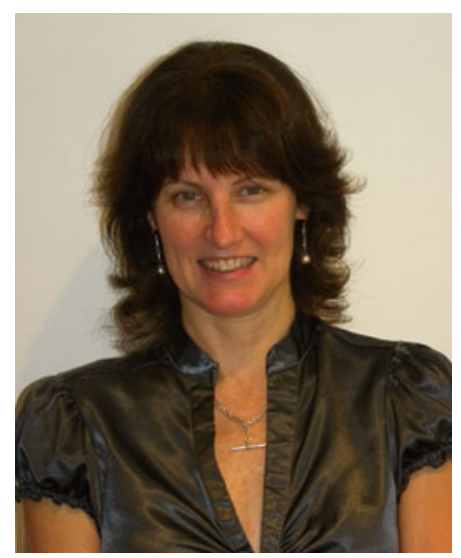

Lindsey Mackay studied chemistry at the University of Auckland, New Zealand, and received her $\mathrm{PhD}$ in organic chemistry from the University of Cambridge, UK, in 1993. After working in a postdoctoral position at the University of Sydney, Australia, she moved to the Australian Government Analytical Laboratory (AGAL). Within AGAL, she set up the Chemical Reference Methods group and AGAL became the designated institute for metrology in chemistry. In 2004, AGAL was merged with the National Measurement Laboratory to become the National Measurement Institute (NMI). Since 2008, she has been the General Manager of Chemical and Biological Metrology at NMI. She also chairs the Organic Analysis Working Group of CCQM (Comité Consultatif pour la Quantité de Matière) and acts as the Australian delegate to the annual CCQM plenary meetings.

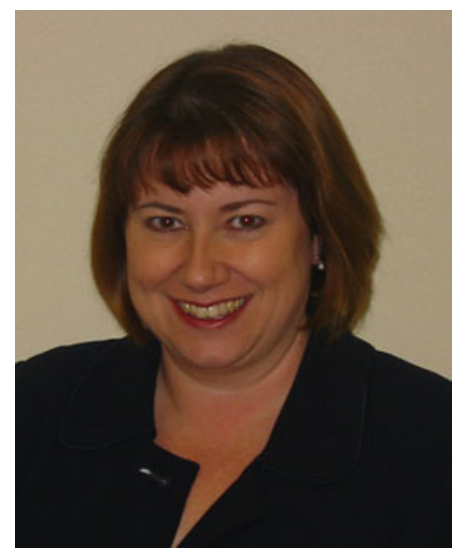

After obtaining a BSc in Analytical Chemistry in 1991, Lorraine Turner worked for 5 years as an analytical chemist in environmental and consumer product testing. She received her MSc in 1993. In 1995, she started as a Lead Assessor for forensic and environmental laboratories at UKAS (United Kingdom Accreditation Service) and later became Accreditation Manager for the chemistry section. In 2009, she was appointed Technical Divisional Director. She is a member of a number of technical and international committees such as the Accreditation Issues Committee of ILAC (International Laboratory Accreditation Cooperation) or working groups of ISO (International Organization for Standardization).

In addition to the expansion of the Editorial Team outlined above, there have also been changes to the Intercontinental Advisory Board. I would like to thank those sincerely that have left the Board. Their long-standing support of ACQUAL contributed to the solid foundations that we want to build on. I also welcome the four newly appointed members.

With the new editorial team, guided by the Intercontinental Advisory Board, and through the continued support of ACQUAL's authors and reviewers, I am very confident that the journal is set to fulfill the information needs of 
researchers, practitioners, and decision makers also in the future and in an increasingly global environment.

Steffen Pauly

Publishing Editor

\section{Reference}

1. Enders P, Günzler H (1998) Paul De Bièvre, on the occasion of his 65th birthday. Accred Qual Assur 3:267 